Article

\title{
Production of Carbohydrates from Cardoon Pre-Treated by Acid-Catalyzed Steam Explosion and Enzymatic Hydrolysis
}

\author{
Alessandro Bertini ${ }^{1}$, Mattia Gelosia ${ }^{1, *}$, Gianluca Cavalaglio ${ }^{1}\left(\mathbb{D}\right.$, Marco Barbanera $^{2}$, \\ Tommaso Giannoni $^{1}{ }^{(D)}$, Giorgia Tasselli ${ }^{1}$, Andrea Nicolini ${ }^{1}$ (D) and Franco Cotana ${ }^{1}$ \\ 1 CIRIAF-Biomass Research Centre, University of Perugia, via G. Duranti 63, 06125 Perugia, Italy; \\ bertini@crbnet.it (A.B.); cavalaglio@crbnet.it (G.C.); giannoni@crbnet.it (T.G.); tasselli@crbnet.it (G.T.); \\ andrea.nicolini@unipg.it (A.N.); franco.cotana@unipg.it (F.C.) \\ 2 Department of Economics Engineering Society and Business Organization (DEIM), University of Tuscia, \\ Largo dell'Università s.n.c., Loc. Riello, 01100 Viterbo, Italy; m.barbanera@unitus.it \\ * Correspondence: gelosia@crbnet.it
}

Received: 11 October 2019; Accepted: 8 November 2019; Published: 11 November 2019

\begin{abstract}
Cardoon (Cynara cardunculus) is a promising crop from which to obtain oilseeds and lignocellulosic biomass. Acid-catalyzed steam explosion is a thermochemical process that can efficiently pre-treat lignocellulosic biomass. The drawback is the production of a high number of carbohydrate degradation products in the liquid fraction that could inhibit microbial growth. In this work, the lignocellulosic biomass of cardoon, gathered from a dedicated field, were used as the raw material for the production of fermentable monosaccharides by employing acid-catalyzed steam explosion. The raw material was pre-soaked with a dilute $1 \%(w / w)$ sulfuric acid solution and then subjected to steam explosion under three different severity conditions. The recovered slurry was separated into solid and liquid fractions, which were individually characterized to determine total carbohydrate and inhibitor concentrations. The slurry and the washed solid fraction underwent enzymatic hydrolysis to release glucose and pentose monosaccharides. By conducting the pre-treatment at $175{ }^{\circ} \mathrm{C}$ for $35 \mathrm{~min}$ and hydrolyzing the obtained slurry, a yield of $33.17 \mathrm{~g}$ of monosaccharides $/ 100 \mathrm{~g}$ of cardoon was achieved. At the same conditions, $4.39 \mathrm{~g}$ of inhibitors/100 $\mathrm{g}$ of cardoon were produced.
\end{abstract}

Keywords: biomass; cardoon; acid-catalyzed steam explosion; enzymatic hydrolysis

\section{Introduction}

Cardoon (Cynara cardunculus) is an herbaceous perennial plant in the Asteraceae family [1]. It is a naturally occurring species comprised of many cultivated forms, which is able to grow in regions with dry climates requiring low levels of fertilization [2,3]. Because of these properties, many cultivars of cardoon are exploited for the production of lignocellulosic biomass and oilseeds, which are potential building blocks for the manufacture of bioplastic and biofuels [4]. Cardoon biomass is mainly made of hemicellulose, cellulose, and lignin. These components together form a complex matrix called lignocellulose [3]. Lignin is a polymer rich in phenols, while cellulose and hemicellulose are two polysaccharides rich in hexose and pentose monomers, respectively [5]. Polysaccharides account for about $50 \%$ of the biomass, while lignin accounts for $15 \%-20 \%$ [6,7]. Since cardoon shows interesting dry yield in terms of both lignocellulose (14-15 tons per hectare) and seeds (1.5-2 tons per hectare), it could become one of the key bioenergy crops in the Mediterranean environment in the future $[2,4,8]$.

The lignocellulosic biomass can be efficiently employed as feedstock for industrial microbiology processes. However, its use is complicated, since the polysaccharide chains of both hemicellulose 
and cellulose are quite stable, meaning the carbohydrates are not readily fermentable using microorganisms [9]. In order to obtain fermentable carbohydrates, lignocellulosic biomass has to undergo treatments capable of hydrolyzing the cellulose and hemicellulose polymers. A first chemical-physical pre-treatment followed by an enzymatic hydrolysis treatment with cellulases and hemicellulases is the most common protocol used in both the research domain and industry [10]. Among pre-treatments, steam explosion is a thermochemical process able to render the cellulose-rich solid fraction (SF) easily hydrolyzed by enzymes [11]. Unfortunately, under these process conditions, almost all of the hemicellulose carbohydrates are degraded into unwanted compounds, such as 5-hydroxymethylfurfural (5-HMF), 2-furaldehyde, and levulinic and formic acids, while hemicellulose acetyls are converted into acetic acid [12]. These compounds, which accumulate in the liquid fraction (LF) of the steam explosion, are potent inhibitors of microbial growth. Due to the presence of inhibitors and low content of hemicellulose-derived carbohydrates, the LF is rarely employed in industrial fermentation [13]. The sulfuric-acid-catalyzed steam explosion could represent a solution to this problem, since it enables the recovery of a significant fraction of monomeric hemicellulose carbohydrates in the LF, at the same time without changing inhibitor production and cellulose digestibility [14]. Additionally, in presence of an acid catalyst, process severity (time and temperature) can be decreased, improving the overall economics of the process [15]. Finally, process simplification can be achieved by removing the solid and liquid separation step of the slurry obtained after the steam explosion, so the whole slurry can be directly used for the enzymatic hydrolysis treatment [16]. This last scenario should be further investigated, since the activity of the cellulolytic enzymes could be inhibited by xylo-oligosaccharides [17] and lignin derivatives [18] released into the LF of the slurry, thus decreasing the enzymatic hydrolysis yield of cellulose.

In this work, the lignocellulosic biomass of cardoon, gathered from a dedicated field in Porto Torres (Sassari), was used as the raw material for the production of fermentable monosaccharides by employing an acid-catalyzed steam explosion followed by an enzymatic hydrolysis treatment. The raw material was pre-soaked with a dilute $1 \%(w / w)$ sulfuric acid solution and then subjected to steam explosion under three different severity conditions to minimize inhibitor production and maximize carbohydrate recovery. The recovered slurry was separated into solid and liquid fractions, which were individually characterized for carbohydrate and inhibitor concentrations. Both the slurry and the washed SF underwent enzymatic hydrolysis to obtain a monosaccharide-rich hydrolysate.

\section{Materials and Methods}

All the reagents utilized in this work were analytical grade and they were purchased from Sigma-Aldrich. The Cellic ${ }^{\circledR}$ CTec2 enzymatic cocktail was provided by Novozymes (Copenhagen, Denmark) . Deionized water was used as the only solvent.

All the samples were characterized according to the National Renewable Energy Laboratory (NREL, Golden, CO, USA) analytical methods for biomass, in order to evaluate their composition [19]. The moisture analysis of solid samples was performed using a HB43-S Halogen Classic plus (Mettler Toledo, Columbus, $\mathrm{OH} 43240$, USA). Monosaccharide and inhibitor concentrations were analyzed using an ultra-high performance liquid chromatography (UHPLC) Dionex UltiMate 3000 (Termo Scientifc, Sunnyvale, CA, USA equipped with a Bio-Rad Aminex HPX-87H column (Biorad, California, USA) thermo-regulated at $50{ }^{\circ} \mathrm{C}$, and a refraction index detector (ERC RefractoMax 520, Termo Scientifc, Waltham, MA, USA), mobile phase $=0.01 \mathrm{~N} \mathrm{H}_{2} \mathrm{SO}_{4}$, flow $0.6 \mathrm{ml} / \mathrm{min}$.

\subsection{Characterization of Raw Material, $S F$, and LF}

Cynara cardunculus stems were kindly provided by Matrica S.p.A. (Porto Torres, Italy) and were already dried. The raw material presented a water content of $8.79 \%(w / w)$ and was characterized in terms of cellulose, hemicellulose, lignin, extractives, pectin, acetyl group, and ash [20]. The SF and LF were characterized for cellulose and hemicellulose content $[20,21]$. The inhibitor formation (5-HMF, 2-furaldehyde, acetic acid, and levulinic acid) was investigated only for LF [21]. 
The $\mathrm{C} 5$ and $\mathrm{C} 6$ monosaccharide and inhibitor concentration in the LF was directly detected by UHPLC. An acid hydrolysis with $\mathrm{H}_{2} \mathrm{SO}_{4}$ of each sample (raw material, $\mathrm{SF}$, and LF) was performed in triplicate to obtain $\mathrm{C} 5$ and $\mathrm{C} 6$ monomers from cellulose and hemicellulose polymers, which were detected by UHPLC. The concentration of polymeric sugars was calculated using an anhydrous correction of 0.88 and 0.90 for $\mathrm{C} 5$ and $\mathrm{C} 6$ carbohydrates, respectively. The remaining acid-insoluble residue was used to calculate the acid-insoluble lignin after removing the ash content.

\subsection{Process Flowchart}

Figure 1 shows the reported experimental process chain performed to treat the lignocellulosic biomass and produce monosaccharide-rich hydrolysates. The raw material was chipped with an industrial chipper, obtaining a heterogeneous mix of woodchips (200-250 mm). The chipped biomass was soaked overnight in a $1 \%(w / w)$ sulfuric acid solution. The solid-liquid ratio used for biomass soaking was 1:10, allowing for a uniform contact between biomass and acid solution, as reported in the literature data [22]. Subsequently, the biomass was removed from the acid bath, drained, and subjected to steam explosion pre-treatment. Following the pre-treatment, the recovered material (slurry) was split into two equal parts. A solid-liquid separation via vacuum filtration using a $60 \mathrm{gr} / \mathrm{m}^{2}$ filter paper (CHMLAB group, Barcellona, Spain) was performed in one of the two parts, obtaining a SF and a LF, respectively. The SF was washed with deionized water (solid-liquid ratio of 1:10) and subjected to enzymatic hydrolysis. The part collected as a slurry was also subjected to enzymatic hydrolysis.

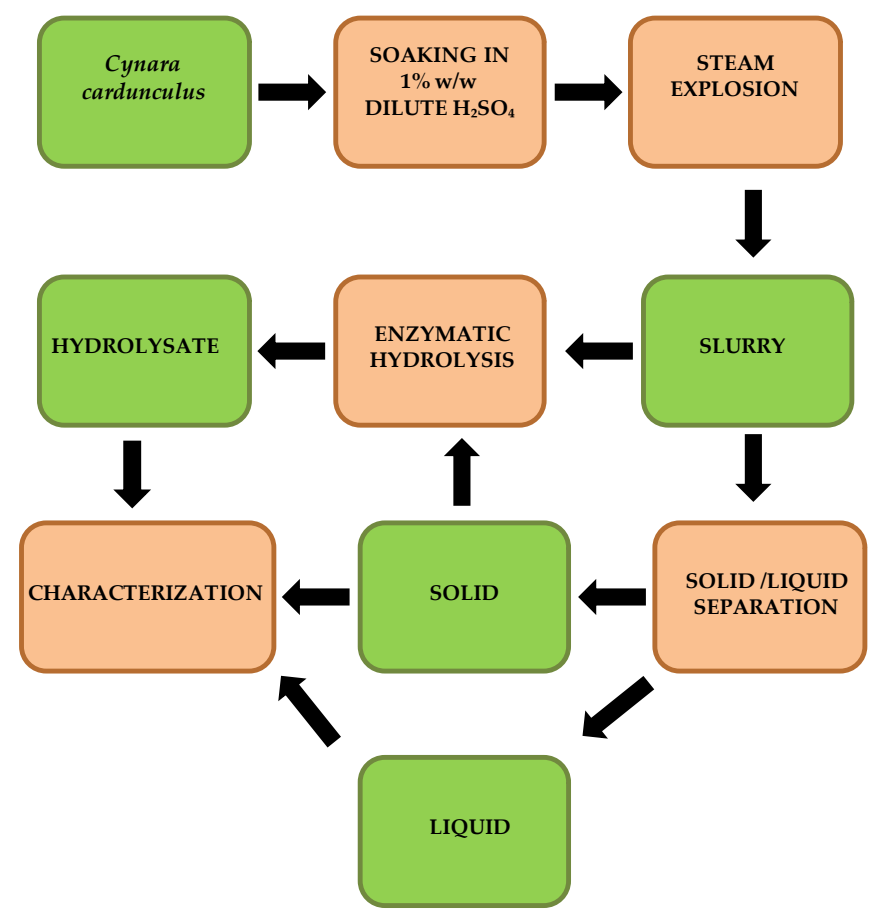

Figure 1. The overall process of the hydrolysates production, starting from Cynara cardunculus biomass.

\subsection{Steam Explosion}

Steam explosion pre-treatment was carried out in an $11 \mathrm{~L}$ pilot-scale reactor (Biochemtex, Tortona, Italy). The feedstock was pre-treated at three different temperatures and with a fixed residence time, as shown in Table 1. 
Table 1. Pre-treatment conditions.

\begin{tabular}{ccc}
\hline Sample Name & Temperature $\left({ }^{\circ} \mathbf{C}\right)$ & Time $(\mathbf{m i n})$ \\
\hline CA1 & 160 & 35 \\
CA2 & 175 & 35 \\
CA3 & 190 & 35 \\
\hline
\end{tabular}

A residence time of $35 \mathrm{~min}$ was chosen to promote hemicellulose hydrolysis and to avoid excessive dilution of the resulting slurry from the incoming steam [23].

Cellulose and hemicellulose recovery into SF and LF after pre-treatment were determined by using Equation (1):

$$
\% \text { Recovery }=\frac{\mathrm{C} \text { or } \mathrm{H} \text { into SF or } \mathrm{LF}}{\mathrm{C} \text { or H into raw material }} \times 100
$$

where $\mathrm{C}$ is the mass of cellulose $(\mathrm{g})$ and $\mathrm{H}$ is the mass of hemicellulose $(\mathrm{g})$.

\subsection{Enzymatic Hydrolysis}

Enzymatic hydrolysis was carried out on both the washed SF and the slurry in $100 \mathrm{ml}$ flasks. In order to assess the best pre-treatment condition, the enzymatic hydrolysis was carried out at a solid loading of $5 \%(w / w)$ and with high enzyme loading of $0.3 \mathrm{~g}$ enzyme/g cellulose. The final weight of each trial was set to $50 \mathrm{~g}$ and it was obtained using a $45 \mathrm{mM}$ citrate buffer solution (pH 5.0). The reaction was conducted in a thermostatic chamber at $50{ }^{\circ} \mathrm{C}$ and under shaking conditions, using an orbital shaker (Phoenix Instrument RS-OS 10) set to $180 \mathrm{rpm}$ for 72 hours. The resulting hydrolysates were characterized for monosaccharide content by UHPLC. The enzymatic hydrolysis yields (EY) of cellulose and hemicellulose were determined by using Equations (2) and (3):

$$
\% \text { EY cellulose }=\frac{\mathrm{G}_{\mathrm{Hy}} \times \mathrm{V}_{\mathrm{Hy}} \times 0.9}{\mathrm{C} \text { into SF }} \times 100
$$

where $\mathrm{G}_{\mathrm{Hy}}$ is the glucose concentration $(\mathrm{g} / \mathrm{L})$ in the hydrolysates, $\mathrm{V}_{\mathrm{Hy}}$ is the hydrolysate volume $(\mathrm{L})$, 0.9 is the anhydrous correction factor for C6 sugars, and C is the mass of cellulose (g).

$$
\% \text { EY hemicellulose }=\frac{\mathrm{H}_{\mathrm{Hy}} \times \mathrm{V}_{\mathrm{Hy}} \times 0.88}{\mathrm{H} \text { into SF }} \times 100
$$

where $\mathrm{H}_{\mathrm{Hy}}$ is the monosaccharides concentration $(\mathrm{g} / \mathrm{L})$ of hemicellulose in the hydrolysates, $\mathrm{V}_{\mathrm{Hy}}$ is the hydrolysate volume (L), 0.88 is the anhydrous correction factor for $\mathrm{C} 5$ sugars, and $\mathrm{H}$ is the mass of hemicellulose (g).

The $\mathrm{pH}$ of the slurry was adjusted to 5 before addition of the buffer. Table 2 shows the conditions of the enzymatic hydrolysis step.

Table 2. Enzymatic hydrolysis conditions used to determine the EY values of cellulose and hemicellulose. Note: $\mathrm{SF}=$ solid fraction; $\mathrm{LF}=$ liquid fraction.

\begin{tabular}{ccccc}
\hline Sample Name & Solid Dry Weight $(\mathbf{g})$ & Water Content $(\mathrm{g})$ & Buffer Solution $(\mathrm{g})$ & Enzyme $(\mathrm{g})$ \\
\hline CA1SF & 2.5 & 10.25 & 38.90 & 0.42 \\
CA2SF & 2.5 & 8.91 & 40.19 & 0.43 \\
CA3SF & 2.5 & 8.81 & 40.29 & 0.42 \\
CA1 slurry & 2.5 & 46.25 & 0.83 & 0.42 \\
CA2 slurry & 2.5 & 39.41 & 7.66 & 0.43 \\
CA3 slurry & 2.5 & 40.91 & 6.17 & 0.42 \\
CA1LF & 0 & 36 & 13.58 & 0.42 \\
CA2LF & 0 & 30.5 & 19.07 & 0.43 \\
CA3LF & 0 & 32.1 & 17.48 & 0.42 \\
\hline
\end{tabular}


In order to assess the contribution of the carbohydrates present in the LF on the final EY of slurry, the LF values of each sample ( $\mathrm{pH}$ adjusted to 5) were subjected to enzymatic hydrolysis under the same process condition. The results obtained were used as "blanks".

The EY value of the slurry was calculated following Equations (1) and (2) and by subtracting the monosaccharides produced by enzymatic hydrolysis of LF in the final yield.

\section{Results and Discussion}

\subsection{Characterization of Raw Material, $S F$, and LF}

The starting biomass was characterized in order to determine its content of cellulose, hemicellulose, acetyls, pectin, extractives, ash, and lignin, as shown in Table 3.

Table 3. Chemical composition of Cynara cardunculus stem.

\begin{tabular}{cccccccc}
\hline Hemicellulose & Cellulose & Acetyls & Pectin & Lignin & Extractives & Ash & Total \\
\hline $15.81 \%$ & $28.11 \%$ & $4.62 \%$ & $4.38 \%$ & $13.08 \%$ & $7.64 \%$ & $8.79 \%$ & $82.43 \%$ \\
\hline
\end{tabular}

Three acid-catalyzed steam explosions were carried out at different temperatures $\left(160{ }^{\circ} \mathrm{C}, 175^{\circ} \mathrm{C}\right.$, and $190^{\circ} \mathrm{C}$ ), producing different slurries, namely CA1, CA2, and CA3. The slurries were split into their respective $\mathrm{SFs}$ and LFs. The goal of biomass pre-treatment is to remove as much hemicellulose as possible, recovering the sugars in the LF; and to enrich the cellulose content in the SF, making it more susceptible to enzymatic hydrolysis. Table 4 reports the SF characterization in terms of cellulose, hemicellulose, and lignin contents $\left(\mathrm{C}_{\text {solid }}, \mathrm{H}_{\text {solid }}\right.$, and $\left.\mathrm{L}_{\text {solid }}\right)$, and cellulose and hemicellulose recovery in the $\mathrm{LF}\left(\mathrm{HR}_{\text {liquid }}\right.$ and $\left.\mathrm{CR}_{\text {liquid }}\right)$ and the $\mathrm{SF}\left(\mathrm{HR}_{\text {solid }}\right.$ and $\left.\mathrm{CR}_{\text {solid }}\right)$ after the steam explosion pre-treatment.

Table 4. Chemical composition of the SF and LF in terms of cellulose (C), hemicellulose $(\mathrm{H})$, and lignin

(L); cellulose and hemicellulose recovery value (R).

\begin{tabular}{cccccccccc}
\hline Sample & $\mathbf{H}_{\text {solid }}$ & $\mathbf{C}_{\text {solid }}$ & $\mathbf{L}_{\text {solid }}$ & $\mathbf{H R}_{\text {solid }}$ & $\mathbf{C R}_{\text {solid }}$ & $\mathbf{H R}_{\text {liquid }}$ & $\mathbf{C R}_{\text {liquid }}$ & $\mathbf{H R}_{\text {total }}$ & $\mathbf{C R}_{\text {total }}$ \\
\hline CA1 & $9.44 \%$ & $55.43 \%$ & $24.99 \%$ & $26.33 \%$ & $86.93 \%$ & $41.02 \%$ & $2.95 \%$ & $67.34 \%$ & $89.88 \%$ \\
CA2 & $5.46 \%$ & $57.27 \%$ & $30.41 \%$ & $16.49 \%$ & $87.56 \%$ & $48.80 \%$ & $4.28 \%$ & $65.29 \%$ & $91.84 \%$ \\
CA3 & $3.61 \%$ & $56.25 \%$ & $36.41 \%$ & $8.87 \%$ & $77.71 \%$ & $30.69 \%$ & $7.14 \%$ & $39.56 \%$ & $84.85 \%$ \\
\hline
\end{tabular}

As expected, at the lowest temperature the SF of sample CA1 contained less cellulose (55.43\%) and more hemicellulose $(9.44 \%)$ than the other samples. An enrichment in cellulose in the SF was observed in the CA2 sample, which had the highest concentration of cellulose among the considered samples. CA3 showed the lowest hemicellulose content, but it also showed a lower cellulose content than CA2. At the highest temperature, the cellulose and hemicellulose contents inside the SF decreased, since hexose and pentose sugars were converted degraded due to the harsh treatment conditions. This observation is supported by total cellulose and hemicellulose recovery values, which decreased at increasing working temperatures, especially for hemicellulose. The highest total hemicellulose recovery was obtained with sample CA1 $(67.34 \%)$, but about $40 \%$ of the hemicellulose was found to be in the SF.

The best result in terms of hemicellulose recovered in the LF was achieved with sample CA2 $(48.80 \%)$, which also showed a total hemicellulose recovery of $65.29 \%$. Additionally, sample CA2 showed the highest total cellulose recovery $(91.84 \%)$.

The recovery of mono- and oligomeric hemicellulose and cellulose in the LF in relation to their raw material content is reported in Figure 2. For each sample, the monomeric form was higher than the oligomeric form for both cellulose and hemicellulose. Due to its crystalline properties, only a small amount of cellulose was hydrolyzed in the LF, suggesting the need to perform an enzymatic hydrolysis treatment on the SF. 


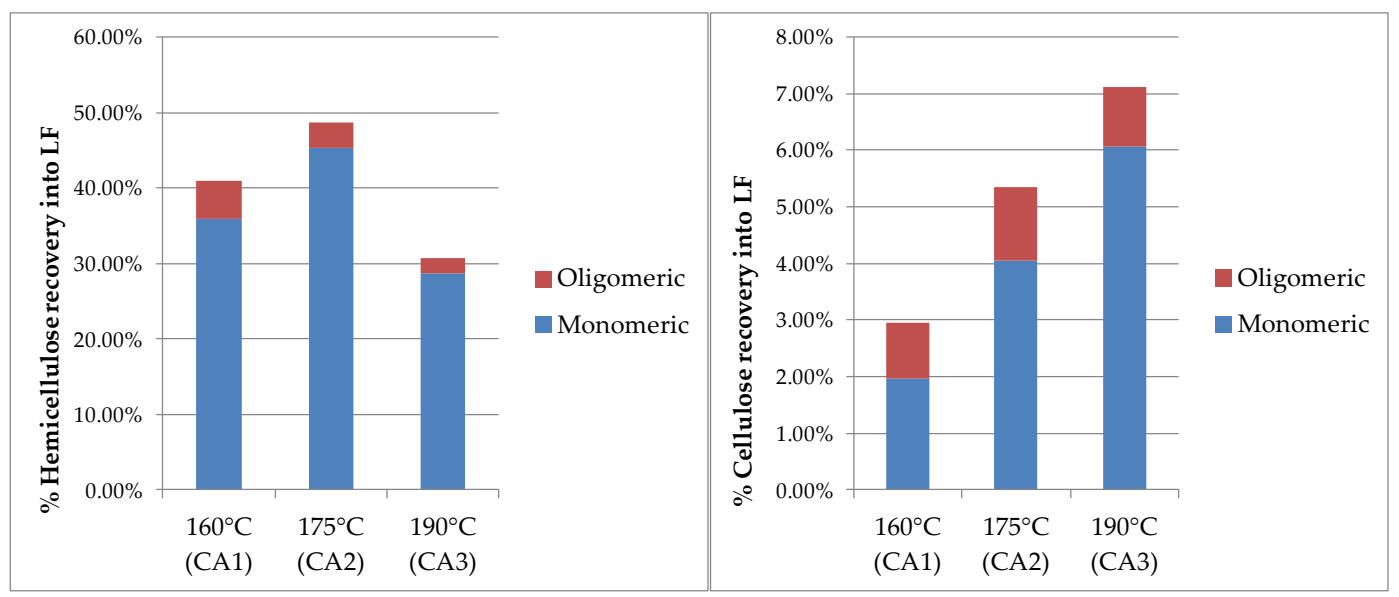

Figure 2. Mono- and oligosaccharides of cellulose and hemicellulose recovered in the LF.

The cellulose recovery in the LF was below $10 \%$ for all the samples, and the highest result was achieved with sample CA3 (7.14\%), followed by CA2 (4.28\%). These values were still higher than the ones obtained using a non-catalyzed steam explosion [24]. On the contrary, the use of acid as the catalyst allowed recovery of a high amount of hemicellulose in the LF, with the maximum reached for CA2 (48.80\%). Also, about $90 \%$ of hemicellulose was present in monomeric form, meaning that the carbohydrates were already usable for subsequent fermentation. In a previous study performed on cardoon without the use of an acid catalyst [24], only $25 \%$ of hemicellulose was recovered in the LF and $50 \%$ was in oligomeric form.

As shown in Figure 3, the total monosaccharide content of the LF appeared to drop after reaching $175^{\circ} \mathrm{C}$, even though a higher amount of hemicellulose was hydrolyzed at $190^{\circ} \mathrm{C}$ (Table 4). A steady increasing trend was instead observed for the inhibitor content, which means that thermal degradation reactions of carbohydrates occurred at every temperature tested. Yuzhen Zhang et al. studied the formation kinetics of inhibitors during the steam explosion process of corn straw, demonstrating that inhibitor formation starts at low temperature and increases as temperature increases [25]. The right balance between monosaccharide recovery and inhibitor production was achieved at both $160{ }^{\circ} \mathrm{C}$ and $175^{\circ} \mathrm{C}$, while at $190^{\circ} \mathrm{C}$ the degradation reactions predominated over hemicellulose hydrolysis. Maximum carbohydrate recovery and minimum inhibitor production were achieved at $175{ }^{\circ} \mathrm{C}$ and $160^{\circ} \mathrm{C}$, respectively. Total inhibitor production was lower than that obtained in other similar studies on biomass pre-treatment; therefore, the liquid could be successfully employed as feedstock for microbial processes, such as lipid accumulation and biogas production. Further experiments on microorganism tolerance to inhibitors should be performed to confirm this last hypothesis.

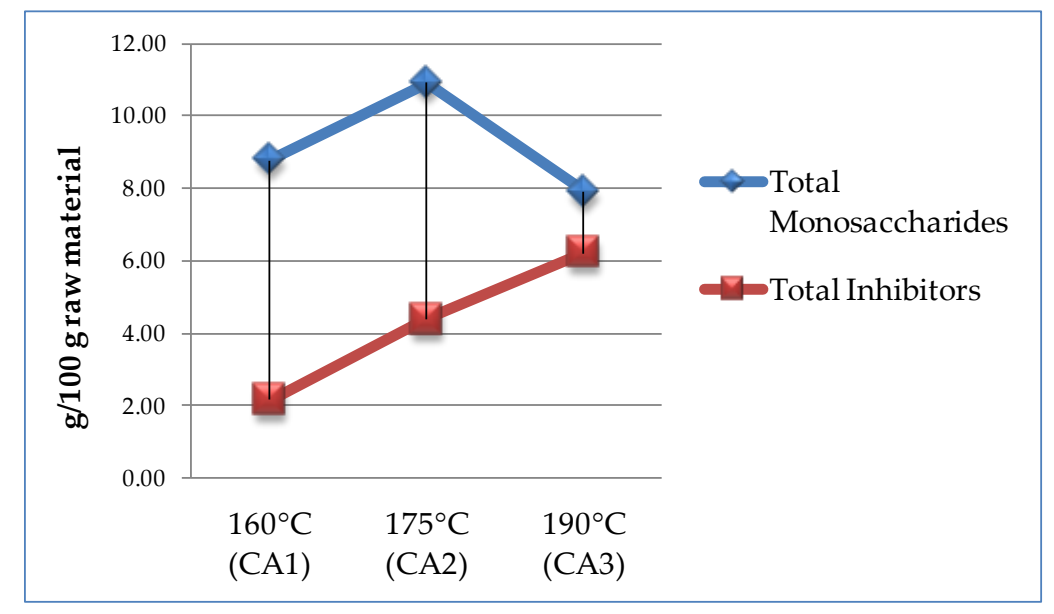

Figure 3. Monosaccharide and inhibitor content in the LF at different pre-treatment conditions. 


\subsection{Enzymatic Hydrolysis}

Enzymatic hydrolysis was performed on both the washed SF and the slurry of each sample in order to test potential inhibitory effects of the liquid on enzymatic activity. Inhibitors released during the pre-treatment step in the LF reduce the hydrolysis activity of enzymes. The main inhibitors are phenols, xylo-oligosaccharides, and monosaccharides (end product inhibition effect) $[17,26]$. Figure 4 shows the final enzymatic hydrolysis yield of cellulose and hemicellulose. About $70 \%$ of cellulose was hydrolyzed in CA2 and CA3 samples, suggesting that a maximum hydrolysis yield was achieved at $175^{\circ} \mathrm{C}$. The same samples showed a similar result in terms of hydrolyzed hemicellulose $(59.27 \%$ and $63.05 \%$, respectively). The slurry of each sample showed the same trend in terms of cellulose hydrolysis, with slightly lower values. However, the difference between yields of the SF and the slurry decreased at increasing temperatures. These positive achievements suggest that slight inhibitory effects are present during cellulose hydrolysis of the slurry pre-treated at temperature equal to or higher than $175^{\circ} \mathrm{C}$. Conversely, a significant inhibition effect was observed for the hydrolysis of slurry-related hemicellulose, with a maximum reduction of the yield observed for CA2 (about a 50\% loss). This inhibition effect was probably due to higher contents of mono- and oligosaccharides in the LF of slurry obtained at $175^{\circ} \mathrm{C}$ (Figure 2) [27]. However, only $16.49 \%$ and $8.87 \%$ of the initial hemicellulose was still present in the SF for the CA2 and CA3 samples, respectively.

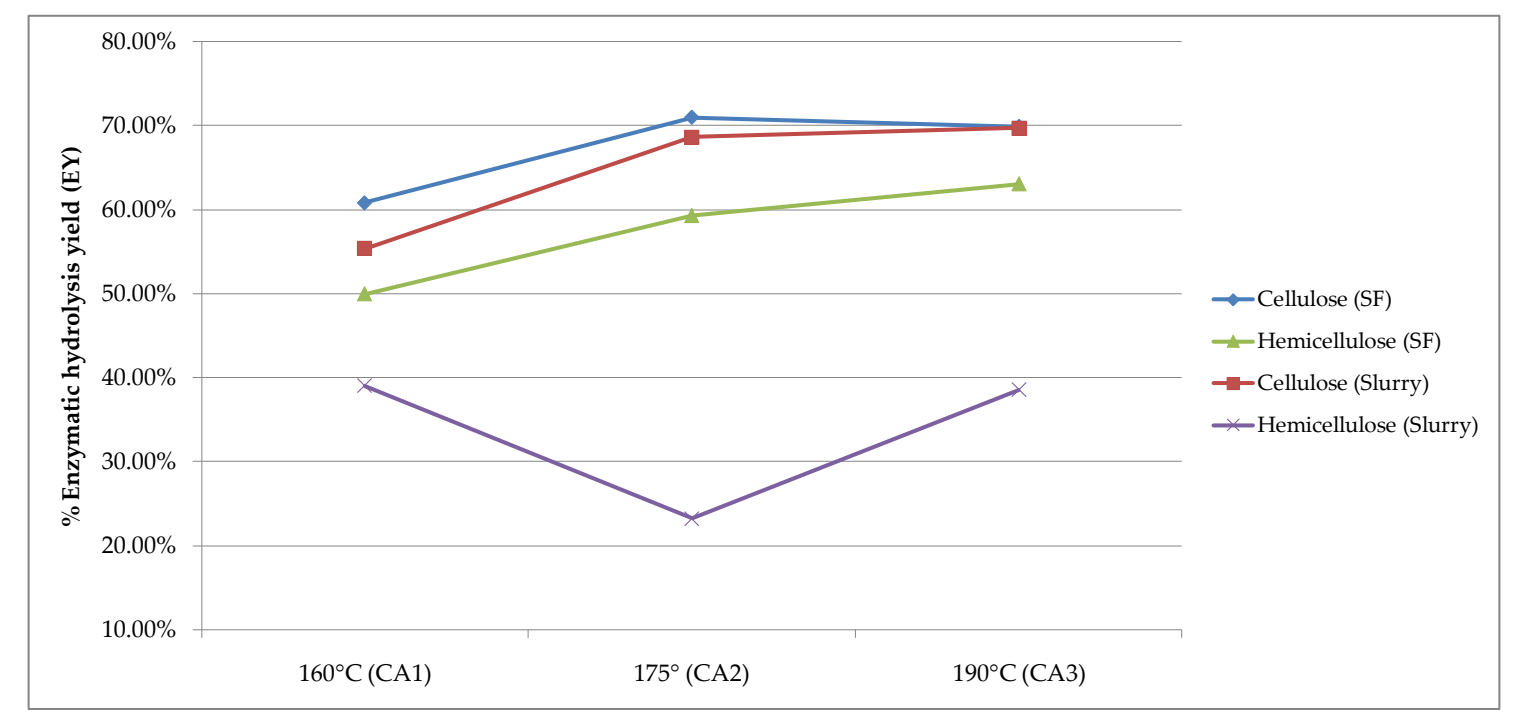

Figure 4. Enzymatic hydrolysis yields of SF and slurries.

The total sugar yield achieved after the acid-catalyzed steam explosion of cardoon, followed by the enzymatic hydrolysis step, are reported in Figure 5. Three different approaches were considered: monosaccharide recovery in the SF's hydrolysate, monosaccharide recovery in the SF's hydrolysate and in the LF, and monosaccharide recovery in the slurry's hydrolysate. CA2 showed higher monosaccharide recovery for all the considered approaches compared with the other two samples. The best result was achieved with a pre-treatment conducted at $175{ }^{\circ} \mathrm{C}$, followed by enzymatic hydrolysis of the resulting slurry, allowing the recovery of $67.4 \%$ of the monosaccharides initially present in the raw material (represented by the dashed line in Figure 5). This is a 57\% improvement over the hydrolysis of the SF alone and a higher monosaccharide recovery than that obtained from the hydrolysates of SF and LF separately. Therefore, the overall process of monosaccharide production could be streamlined by avoiding separation of the LF from the SF before the enzymatic hydrolysis step. 


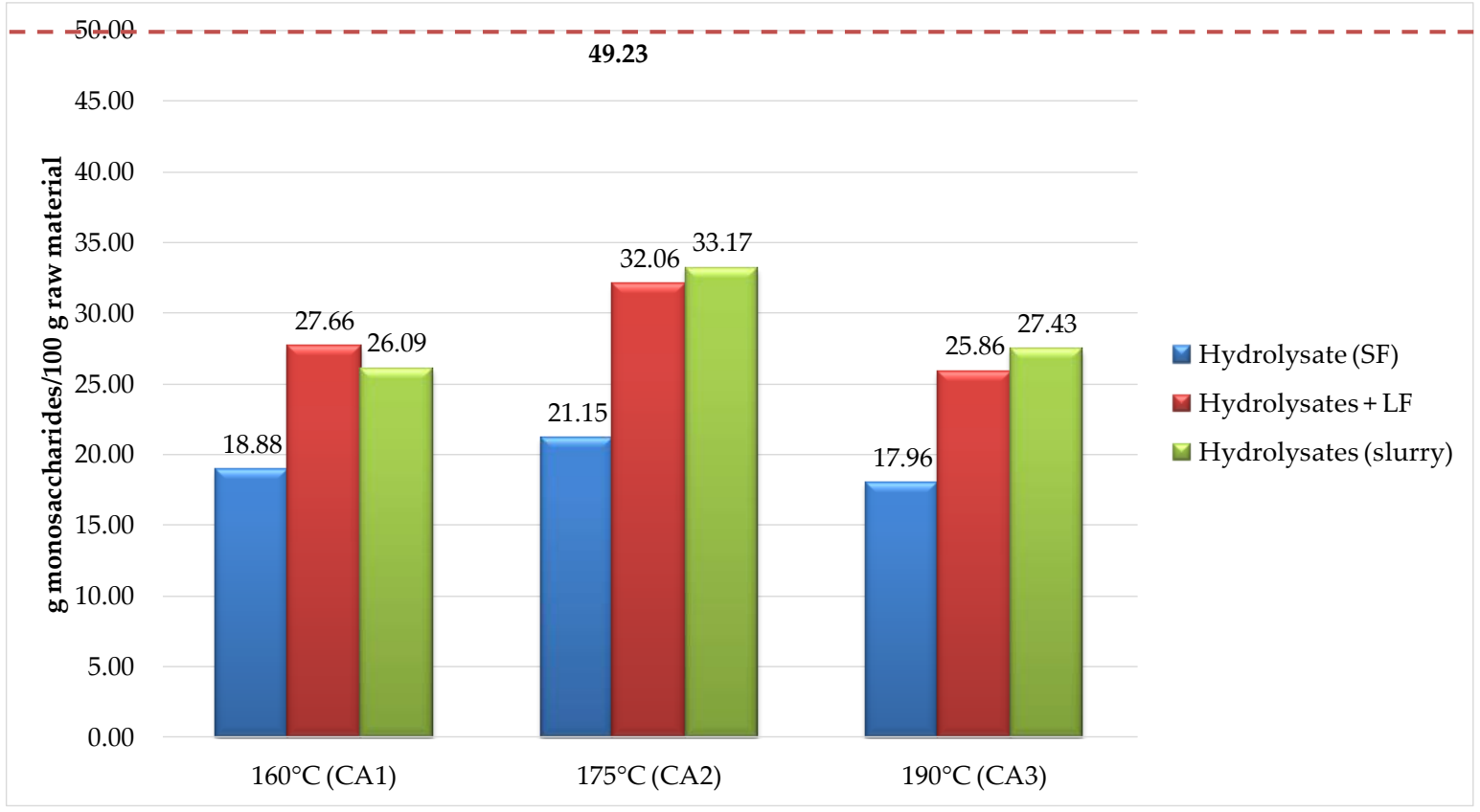

Figure 5. Total amount of monosaccharides recovered after pre-treatment and enzymatic hydrolysis; the dashed line corresponds to the maximum theoretical value.

These outcomes were analogous to those obtained in a study with a similar cardoon pre-treatment approach [28] and better than those obtained in another study using non-catalyzed steam explosion [24]. In the former, monosaccharide recovery of $41 \mathrm{~g} / 100 \mathrm{~g}$ raw material was achieved (about $70 \%$ of the maximum theoretical value). In the latter, a similar enzymatic hydrolysis yield was obtained (70-75\%), but almost no carbohydrates were recovered in the LF (below $3 \mathrm{~g} / 100 \mathrm{~g}$ raw material).

\section{Conclusions}

In this work, Cynara cardunculus was used as the raw material for the optimization of monosaccharide production using acid-catalyzed steam explosion and enzymatic hydrolysis. Before the pre-treatment, the biomass was chipped and soaked in a dilute $1 \%(w / w)$ sulfuric acid solution. By conducting the pre-treatment at $175{ }^{\circ} \mathrm{C}$ for 35 minutes, about $50 \%$ of hemicellulose-derived monosaccharides (10.91 g/100 g raw material) were recovered in the liquid fraction, maintaining low inhibitor production ( $4.39 \mathrm{~g} / 100 \mathrm{~g}$ raw material). The enzymatic hydrolysis performed on the recovered SF showed a hydrolysis rate of $70.98 \%$ for cellulose and $59.27 \%$ for hemicellulose. A comparable enzymatic hydrolysis yield was observed using the whole slurry, producing $33.17 \mathrm{~g}$ of cardoon monosaccharides/100 $\mathrm{g}$ ( $67.4 \%$ of maximum theoretical yield). Therefore, the elimination of the liquid/solid separation step after the steam explosion can lead to an overall simplification of industrial microbiology processes, such as the production of bio-ethanol and lipid accumulation in oleaginous yeasts. Additional works employing the recovered slurry hydrolysates in microbial growth should be performed to verify the tolerance to inhibitor compounds.

Author Contributions: A.B. and G.T., carried out experiments on carbohydrates production, T.G. carried out UHPLC analyses, M.G. designed the study and drafted the manuscript, M.B. carried out the statistical analyses, G.C. and A.N. drafted the manuscript, and F.C. designed the study and supervised the research. All authors read and approved the manuscript.

Funding: This research was funded by the Italian Ministry for Education and Scientific Research (MIUR) through the project: "Biofeedstock- Sviluppo di piattaforme tecnologiche integrate per la valorizzazione di biomasse residuali" (project No PON_BIOFEEDSTOCK_ARS01_00985).

Acknowledgments: We would like to thank Matrica for supplying the cardoon biomass and Novozymes for supplying the enzymatic cocktails used in the experimentation. 
Conflicts of Interest: The authors declare no conflict of interest.

\section{References}

1. Cajarville, C.; González, J.; Repetto, J.; Alvir, M.; Rodríguez, C. Nutritional evaluation of cardoon (cynara cardunculus) seed for ruminants. Anim. Feed Sci. Technol. 2000, 87, 203-213. [CrossRef]

2. Angelini, L.G.; Ceccarini, L.; o Di Nasso, N.N.; Bonari, E. Long-term evaluation of biomass production and quality of two cardoon (Cynara cardunculus L.) cultivars for energy use. Biomass Bioenergy 2009, 33, 810-816. [CrossRef]

3. Ciancolini, A.; Alignan, M.; Pagnotta, M.A.; Vilarem, G.; Crinò, P. Selection of italian cardoon genotypes as industrial crop for biomass and polyphenol production. Ind. Crops Prod. 2013, 51, 145-151. [CrossRef]

4. Fernández, J.; Curt, M.D.; Aguado, P.L. Industrial applications of Cynara cardunculus L. For energy and other uses. Ind. Crops Prod. 2006, 24, 222-229. [CrossRef]

5. Francaviglia, R.; Bruno, A.; Falcucci, M.; Farina, R.; Renzi, G.; Russo, D.E.; Sepe, L.; Neri, U. Yields and quality of Cynara cardunculus L. Wild and cultivated cardoon genotypes. A case study from a marginal land in central Italy. Eur. J. Agron. 2016, 72, 10-19. [CrossRef]

6. Fernandes, M.C.; Ferro, M.D.; Paulino, A.F.C.; Chaves, H.T.; Evtuguin, D.V.; Xavier, A.M.R.B. Comparative study on hydrolysis and bioethanol production from cardoon and rockrose pretreated by dilute acid hydrolysis. Ind. Crops Prod. 2018, 111, 633-641. [CrossRef]

7. Ligero, P.; Villaverde, J.J.; Vega, A.; Bao, M. Pulping cardoon (Cynara cardunculus) with peroxyformic acid (milox) in one single stage. Bioresour. Technol. 2008, 99, 5687-5693. [CrossRef] [PubMed]

8. Foti, S.; Mauromicale, G.; Raccuia, S.A.; Fallico, B.; Fanella, F.; Maccarone, E. Possible alternative utilization of Cynara spp.: I. Biomass, grain yield and chemical composition of grain. Ind. Crops Prod. 1999, 10, 219-228. [CrossRef]

9. Kumar, R.; Singh, S.; Singh, O.V. Bioconversion of lignocellulosic biomass: Biochemical and molecular perspectives. J. Ind. Microbiol. Biotechnol. 2008, 35, 377-391. [CrossRef] [PubMed]

10. Mosier, N.; Wyman, C.; Dale, B.; Elander, R.; Lee, Y.; Holtzapple, M.; Ladisch, M. Features of promising technologies for pretreatment of lignocellulosic biomass. Bioresour. Technol. 2005, 96, 673-686. [CrossRef] [PubMed]

11. Hendriks, A.; Zeeman, G. Pretreatments to enhance the digestibility of lignocellulosic biomass. Bioresour. Technol. 2009, 100, 10-18. [CrossRef] [PubMed]

12. Jacquet, N.; Maniet, G.; Vanderghem, C.; Delvigne, F.; Richel, A. Application of steam explosion as pretreatment on lignocellulosic material: A review. Ind. Eng. Chem. Res. 2015, 54, 2593-2598. [CrossRef]

13. Palmqvist, E.; Hahn-Hägerdal, B. Fermentation of lignocellulosic hydrolysates. II: Inhibitors and mechanisms of inhibition. Bioresour. Technol. 2000, 74, 25-33. [CrossRef]

14. Ballesteros, M.; Negro, M.J.; Manzanares, P.; Ballesteros, I.; Sáez, F.; Oliva, J.M. Fractionation of cynara cardunculus (cardoon) biomass by dilute-acid pretreatment. In Applied Biochemistry and Biotecnology; Springer: Berlin, Germany, 2007; pp. 239-252.

15. Schell, D.; Torget, R.; Power, A.; Walter, P.; Grohmann, K.; Hinman, N. A technical and economic analysis of acid-catalyzed steam explosion and dilute sulfuric acid pretreatments using wheat straw or aspen wood chips. Appl. Biochem. Biotechnol. 1991, 28, 87. [CrossRef]

16. Bondesson, P.M.; Galbe, M.; Zacchi, G. Ethanol and biogas production after steam pretreatment of corn stover with or without the addition of sulphuric acid. Biotechnol. Biofuels 2013, 6, 11. [CrossRef] [PubMed]

17. Duarte, G.C.; Moreira, L.R.S.; Jaramillo, P.M.D.; Filho, E.X.F. Biomass-derived inhibitors of holocellulases. BioEnergy Res. 2012, 5, 768-777. [CrossRef]

18. Jing, X.; Zhang, X.; Bao, J. Inhibition performance of lignocellulose degradation products on industrial cellulase enzymes during cellulose hydrolysis. Appl. Biochem. Biotechnol. 2009, 159, 696. [CrossRef] [PubMed]

19. Sluiter, J.; Sluiter, A. Summative Mass Closure; NREL NREL/TP-510-48087; National Renewable Energy Lab. (NREL): Golden, CO, USA, 2010; pp. 1-10.

20. Sluiter, A.; Hames, B.; Ruiz, R.; Scarlata, C.; Sluiter, J.; Templeton, D.; Crocker, D. Determination of structural carbohydrates and lignin in biomass. Labor. Anal. Proced. 2008, 1617, 1-16. 
21. Sluiter, A.; Hames, B.; Ruiz, R.; Scarlata, C.; Sluiter, J.; Templeton, D. Determination of Sugars, Byproducts, and Degradation Products in Liquid Fraction Process Samples; National Renewable Energy Laboratory (NREL): Golden, CO, USA, 2006.

22. Tao, L.; Schell, D.; Davis, R.; Tan, E.; Elander, R.; Bratis, A. Nrel 2012 Achievement of Ethanol Cost Targets: Biochemical Ethanol Fermentation via Dilute-Acid Pretreatment and Enzymatic Hydrolysis of Corn Stover; National Renewable Energy Lab. (NREL): Golden, CO, USA, 2014.

23. Ballesteros, I.; Negro, M.J.; Oliva, J.M.; Cabañas, A.; Manzanares, P.; Ballesteros, M. Ethanol Production from Steam-Explosion Pretreated Wheat Straw. In Proceedings of the Twenty-Seventh Symposium on Biotechnology for Fuels and Chemicals, Denver, CO, USA, 1-4 May 2005; Springer: Berlin, Germany, 2006; pp. 496-508.

24. Cotana, F.; Cavalaglio, G.; Gelosia, M.; Coccia, V.; Petrozzi, A.; Ingles, D.; Pompili, E. A comparison between shf and sssf processes from cardoon for ethanol production. Ind. Crops Prod. 2015, 69, 424-432. [CrossRef]

25. Zhang, Y.; Wang, L.; Chen, H. Formation kinetics of potential fermentation inhibitors in a steam explosion process of corn straw. Appl. Biochem. Biotechnol. 2013, 169, 359-367. [CrossRef] [PubMed]

26. Takagi, M. Inhibition of cellulase by fermentation products. Biotechnol. Bioeng. (U. S.) 1984, $26,1506-7$. [CrossRef] [PubMed]

27. Qing, Q.; Yang, B.; Wyman, C.E. Xylooligomers are strong inhibitors of cellulose hydrolysis by enzymes. Bioresour. Technol. 2010, 101, 9624-9630. [CrossRef] [PubMed]

28. Ballesteros, I.; Ballesteros, M.; Manzanares, P.; Negro, M.J.; Oliva, J.M.; Sáez, F. Dilute sulfuric acid pretreatment of cardoon for ethanol production. Biochem. Eng. J. 2008, 42, 84-91. [CrossRef]

(C) 2019 by the authors. Licensee MDPI, Basel, Switzerland. This article is an open access article distributed under the terms and conditions of the Creative Commons Attribution (CC BY) license (http://creativecommons.org/licenses/by/4.0/). 